\title{
BMJ Open Quality Establishing a new national standard for the documentation of regional anaesthesia in Ireland
}

\author{
Peter James Moran, ${ }^{1}$ Paul Fennessy, ${ }^{2}$ Mark Zachary Johnson ${ }^{3}$
}

To cite: Moran PJ, Fennessy $P$, Johnson MZ. Establishing a new national standard for the documentation of regional anaesthesia in Ireland.BMJ Open Quality 2017;6:e000210. doi:10.1136/ bmjoq-2017-000210

PJM and PF contributed equally.

Received 20 September 2017 Revised 27 October 2017 Accepted 12 November 2017

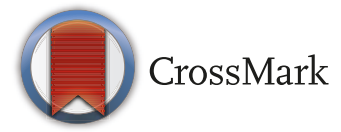

${ }^{1}$ Department of Anaesthesia, Adelaide and Meath Hospital, Dublin, Ireland

${ }^{2}$ Department of Anaesthesia, Our Lady's Children's Hospital Crumlin, Crumlin, Ireland

${ }^{3}$ Department of Anaesthesia, National Maternity Hospital, Dublin, Ireland

Correspondence to Dr Paul Fennessy; paulfeno@hotmail.com

\section{PROBLEM}

It is important that a number of safety measures are taken to ensure the most suitable regional anaesthesia (RA) technique is performed for the correct patient. These measures include obtaining patient consent, checking all equipment and drugs, ensuring appropriate monitoring and performance of a correct surgical site check.

Once the regional block is performed, it is vital to accurately document the procedure in detail. This is an important means of communication between the anaesthetist and surgical team, the nursing staff and allied health professionals in the postoperative period.

The aim of our RA Procedural Record (RAPR) is primarily to establish a minimum standard of documentation across anaesthesia departments in Ireland. While the record leads to more accurate documentation, it also acts as a reminder to follow the appropriate steps in safely performing a RA block, therefore reducing the potential for performing an inappropriate or contraindicated procedure.

\section{BACKGROUND}

RA involves the deposition of local anaesthetic around a nerve using a needle. It can be performed by landmark technique or guided with ultrasound or nerve stimulation device. RA can be used as a sole anaesthetic technique or for the purpose of intraoperative and postoperative analgesia. It may also be combined with either sedation or general anaesthesia.

While RA can provide effective analgesia and anaesthesia for patients undergoing surgical procedures, there may be a risk of nerve injury or other undesirable complications associated with the technique; therefore, accurate documentation is important. It has been shown in other countries that a standardised record improves documentation ${ }^{1}$ and aids meeting legal requirements ${ }^{2}$ and acts as a source for education and audit. ${ }^{3}$

\section{STRATEGY}

Via a national email survey, we measured existing means of RA documentation in Ireland. This included review of RA recording documents in all anaesthetic departments nationally. In order to achieve this, we contacted RA leads in each department to ensure accurate collection of information. We found considerable variation in the quality and format of these documents between anaesthesia departments nationally. Some institutions employed a detailed tick-box or free text box based document while others documented the procedure electronically.

We appreciated that while a quality improvement initiative performed at a local level would have been important, with such a lack of consistent RA recording documents throughout Ireland, we felt that a national level project was indicated. We accomplished this in three ways:

1. We attained the support of our national RA body, the Irish Society of Regional Anaesthesia (ISRA), for purposes of promotion and distribution of our RAPR.

2. We sought opinions from local and international experts regarding the content of the record.

3. We used Plan-Do-Study-Act (PDSA) cycles to gain feedback from end users at a local level and introduce reforms efficiently.

We designed the first draft of the ISRA RAPR, which was piloted across four hospitals and feedback contributed to the first PDSA cycle. Feedback was sought from all consultants and trainees via a locally based liaison in each of the four hospitals. Feedback related to:

1. Ease of use,

2. Level of detail,

3. Legal implications,

4. Omitted information. 


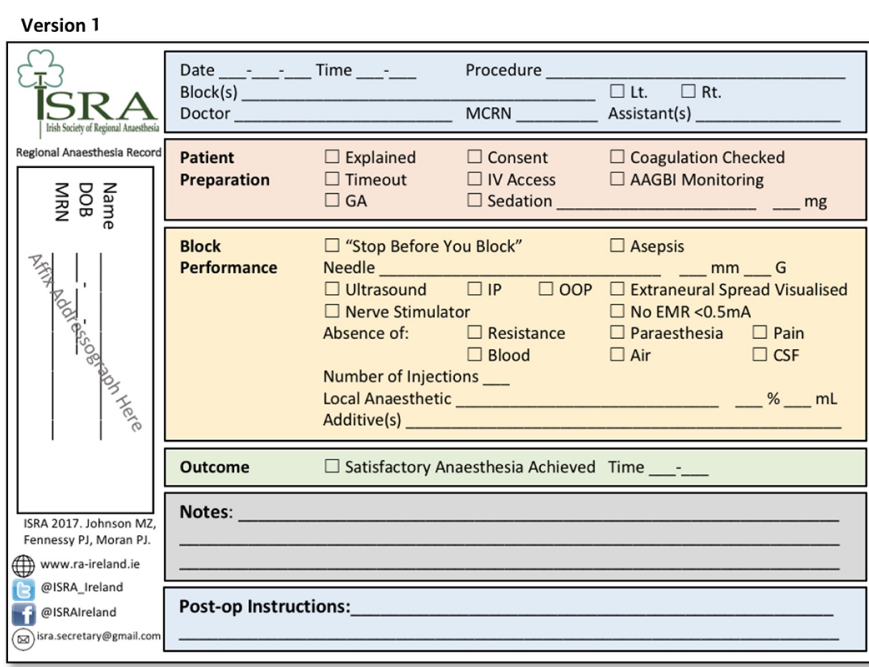

Figure 1 Irish Society of Regional Anaesthesia (ISRA) Regional Anaesthesia Procedural Record version 1 and version 2.

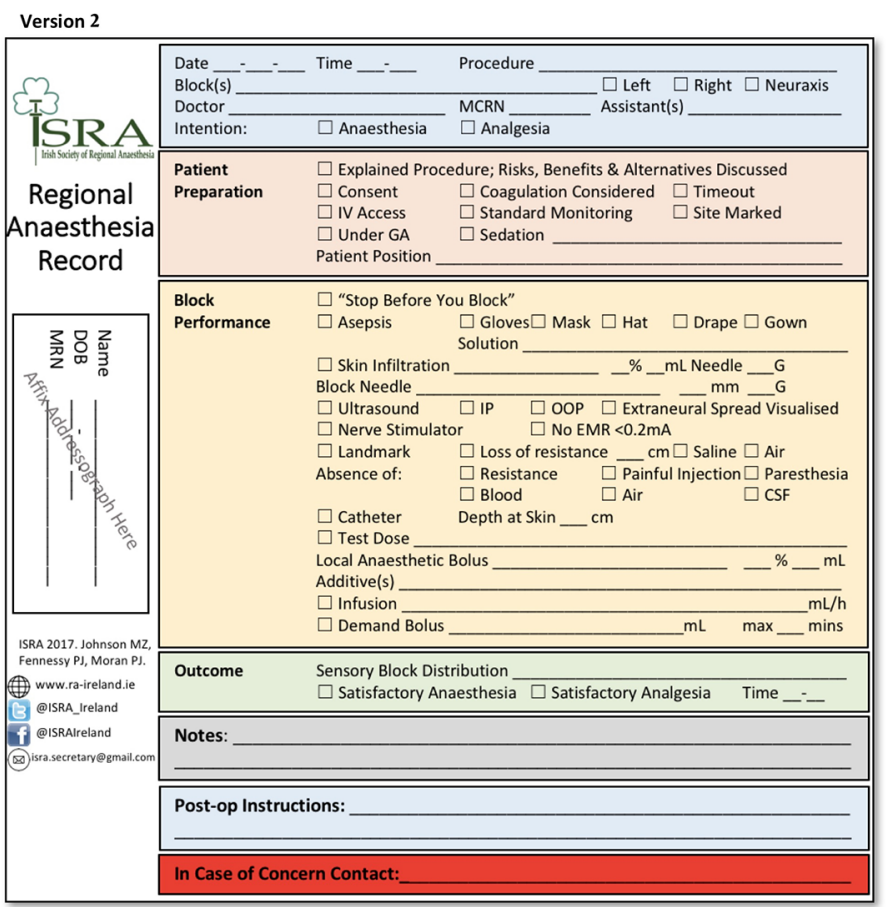

This feedback then informed the subsequent changes made to the original draft document.

\section{RESULTS}

Once feedback was reviewed, we designed the original draft of the ISRA RAPR. The record was presented at the national ISRA meeting. Each of the 100+ delegates who attended the meeting received samples of the ISRA RAPR for use in their own institution. In addition, copies of the record were posted to a practising RA anaesthetist in every public hospital anaesthesia department in Ireland.

After 6 months, as part of a subsequent PDSA cycle, we audited our project by means of an anonymous electronic survey distributed nationally. We received feedback from 106 anaesthetists at both consultant and non-consultant level. Feedback topics were similar to $1-4$ above with a further section for potential improvements.

Of those surveyed, $98.1 \%$ supported the concept of a standardised RA record and $94.2 \%$ felt the record contained sufficient detail for adequate documentation of RA procedures. Over $90 \%$ of anaesthetists felt it would improve documentation and patient safety, aid communication and act as an audit tool.

We also received feedback regarding suggestions for potential improvement. Subsequent document changes were based on these suggestions, and further advise from national and international experts. The inclusions of catheter and neuraxial (spinal and epidural) block techniques were among the most frequently cited recommendations, both of which are included in an updated version of the ISRA RAPR (figure 1). Although rare, RA techniques may have serious life-threatening complications that require prompt skilled intervention. To enhance patient safety, we included a space specifically for contact details in case of concern.

We presented our national quality improvement project at the 36th Annual European Society of Regional Anaesthesia (ESRA) Congress where it was warmly received. We are currently working with the ESRA council to establish an international guideline for the documentation of RA procedures, which will be the first of its kind.

\section{CONCLUSION}

At the outset, our aim was to instigate a change for the better regarding the documentation of RA in Ireland. The ISRA RAPR aims to provide a minimum standard of documentation and improve patient safety on a national level. Furthermore, it will act as an educational resource for both anaesthesia trainees and consultants alike. It may also serve as a valuable audit tool in the future.

The ISRA RAPR and its concept have been well received nationally and internationally. The support of our national body, ISRA, was key to the implementation of our RAPR. We also felt that liaising with well-respected international experts improved the validity of our project.

The use of PDSA cycles also aided in addressing issues with the original record and allowed us to respond efficiently to issues that arose. Feedback from end users at a national level was also critical to the success of our project.

The successful introduction of this record has shown that standards may be effectively developed in areas with no precedent through close liaison with experts and rigorous testing.

We will continue to use PDSA cycles at regular intervals in order to update and improve our record. In addition to 
regular PDSA cycles, individuals can provide continuous feedback and reorder RAPRs via an ISRA email set-up for ongoing quality improvement purposes relating to our project.

Following the presentation of our quality improvement project at the Annual ESRA Conference 2017, the ESRA council have voted to adopt our project and use it as a basis to introduce international guidelines and minimum standards for the documentation of RA procedures throughout Europe.

Acknowledgements We would like to acknowledge the Irish Society of Regional Anaesthesia for supporting this quality improvement project. We would also like to thank Barrie Fischer for his expert guidance with this project.

Contributors MZJ pioneered and designed the ISRA RAPR. He oversaw the project and paper submission as a whole and also presented our project at the European Society of Regional Anaesthesia annual meeting. PJM wrote the manuscript and also presented the original RAPR at the ISRA national meeting. PF also wrote the manuscript. He also drafted and distributed the national survey and collected feedback. PJM and PF contributed equally to this paper. All three authors contributed to the final design and contents of the ISRA RAPR.

Competing interests None declared.
Patient consent Not obtained.

Provenance and peer review Not commissioned; externally peer reviewed.

Open Access This is an Open Access article distributed in accordance with the Creative Commons Attribution Non Commercial (CC BY-NC 4.0) license, which permits others to distribute, remix, adapt, build upon this work non-commercially, and license their derivative works on different terms, provided the original work is properly cited and the use is non-commercial. See: http://creativecommons.org/ licenses/by-nc/4.0/

(c) Published by the BMJ Publishing Group Limited. For permission to use (where not already granted under a licence) please go to http://www.bmj.com/company/ products-services/rights-and-licensing/

\section{REFERENCES}

1 Hudson P, Gnanaseakaran S, Knowles M. Improvement in documentation of epidural insertion with the addition of a sticker to the anaesthetic chart: an audit cycle. Reg Anesth Pain Med 2008;33:e34.

2 Gerancher JC, Viscusi ER, Liguori GA, et al. Development of a standardized peripheral nerve block procedure note form. Reg Anesth Pain Med 2005;30:67-71.

3 Matthews J, Rutter S, Paul R. Standardised peripheral nerve block label can improve documentation: 251. Reg Anesth Pain Med 2007;32:128. 